\title{
The effects of dentate granule cell destruction on behavioural activity and Fos protein expression induced by systemic methamphetamine in rats
}

\author{
${ }^{1}$ Kunihiko Tani, ${ }^{1,3}$ Masaomi Iyo, ${ }^{1,4}$ Hideo Matsumoto, ${ }^{1}$ Masayoshi Kawai, ${ }^{*, 1}$ Katsuaki Suzuki, \\ 'Yasuhide Iwata, 'Taketoshi Won, ${ }^{1}$ Toshio Tsukamoto, ' $Y$ oshimoto Sekine, ${ }^{1}$ Masatsuna Sakanoue, \\ ${ }^{2,3}$ Kenji Hashimoto, ' $Y u t a k a$ Ohashi, ${ }^{1}$ Nori Takei \& ${ }^{1}$ Norio Mori
}

${ }^{1}$ Department of Psychiatry and Neurology, Hamamatsu University School of Medicine, 1-20-1 Handayama, Hamamatsu, 431-3192, Japan and ${ }^{2}$ Tokyo Laboratories, Pharmaceutical Research Division, Welfide Co., 3-7-25 Koyata-cho, Iruma-shi, 358-0026, Japan

1 We destroyed dentate granule cells unilaterally or bilaterally by means of intrahippocampal injection of colchicine in rats. Subsequently, we observed behavioural changes following the intraperitoneal injection of $2 \mathrm{mg} \mathrm{kg}^{-1}$ methamphetamine or saline, in addition to quantitatively assessing Fos protein expression in several brain regions, including the medial prefrontal cortex, cingulate cortex, piriform cortex, dorsal striatum, and nucleus accumbens.

2 Bilaterally lesioned animals, when administered saline, showed a marked increase in locomotor activity compared with those of non-lesioned animals. With respect to the methamphetamine response, bilateral destruction resulted in a marked enhancement of locomotor activity, while the unilateral destruction led to a marked increase in rotation predominantly contralateral to the lesioned side, with no identifiable change in locomotor activity.

3 Bilaterally lesioned animals, when administered saline and having undergone an immunohistological examination, showed a marked increase in Fos expression in both sides of the nucleus accumbens. Bilaterally lesioned animals administered methamphetamine showed a marked increase in Fos expression in the right and left sides of all regions tested. Unilaterally lesioned animals administered methamphetamine showed a significant and bilateral enhancement in Fos expression in the medial prefrontal and cingulate cortices, and a marked and unilateral (ipsilateral to the lesioned side) enhancement of Fos protein in the piriform cortex, dorsal striatum, and nucleus accumbens. 4 The present findings suggest that dentate granule cells regulate methamphetamine-associated behavioural changes through the function of widespread areas of the brain, mostly the nucleus accumbens.

British Journal of Pharmacology (2001) 134, 1411-1418

Keywords: Dentate granule cell; nucleus accumbens; colchicine; methamphetamine; locomotor activity; rotation; Fos protein

Abbreviations: BL, bilateral lesion; C, control; UL, unilateral lesion

\section{Introduction}

The hippocampus, a structural part of the limbic system, receives its primary afferent inputs from the polymodal association areas of the entorhinal cortex. The hippocampus, in turn, sends outputs to the nucleus accumbens (Groenewegen et al., 1987), dorsal striatum (Groenewegen et al., 1987), and neocortical areas (Jay et al., 1989; White et al., 1990; Jay \& Witter, 1991), which have been implicated in the production and modulation of locomotor activity, rotational movement, and stereotyped behaviour induced by the indirect dopamine agonists, methamphetamine and amphetamine (Pijnenburg \& Van Rossum, 1973; Kelly et al., 1975; Carboni

\footnotetext{
*Author for correspondence; E-mail: katsuaki@hama-med.ac.jp Current addresses: ${ }^{3}$ Department of Psychiatry, School of Medicine, Chiba University, 1-33, Yayoi-cho, Inage-ku, Chiba, 263-8522, Japan; ${ }^{4}$ Department of Psychiatry, School of Medicine, Tokai University, 1117 Kitakaname, Hiratsuka-shi, Kanagawa, 259-1292, Japan
}

et al., 1989; Colle \& Wise, 1991; Antoniou \& Kafetzopoulos, 1992). Lesion placement in the bilateral hippocampi, induced by aspiration (Whishaw \& Mittleman, 1991; Mittleman et al., 1993), or intrahippocampal injection of either ibotenic acid (Lipska et al., 1992) or combined kainic acid/colchicine (Wilkinson et al., 1993; Schaub et al., 1997), has been shown to greatly enhance amphetamine-induced locomotor activity in rats. Hippocampal unilateral lesions have also been seen to cause an increase in rotational activity after the administration of amphetamine (Glick et al., 1980). Accordingly, damage to the hippocampus, its intrinsic neuronal populations, or its network of afferent and efferent fibres may influence amphetamine-induced behavioural changes. Furthermore, selective and bilateral destruction of the dentate granule cells, followed by the microinjection of amphetamine into both sides of the nucleus accumbens, has resulted in a significant increase in locomotor activity (Emerich \& Walsh, 1990). This finding suggests functional interactions between 
the dentate granule cells and the nucleus accumbens that are expressed as perturbations in locomotor activity. However, the effects of manipulation of the dentate granule cells on the dynamics of other brain structures, which are associated with amphetamine- or methamphetamine-induced behaviours and which receive dopaminergic innervations, have not been adequately explored.

The c-fos gene has provided a useful marker to trace the effects of pharmacological, electrical, and physiological stimuli in the central nervous system, because these stimuli immediately cause mature neurons to induce c-fos (Morgan \& Curren, 1991). Immunocytochemistry has indicated that methamphetamine administration produces Fos-like immunoreactivity in a wide variety of brain areas of the rat, and that it dose-dependently increases the density of Foslike immunoreactive cells (Umino et al., 1995). Therefore, this method is useful to investigate regional changes in neuronal activity associated with methamphetamine administration.

In the present study, we destroyed the dentate granule cells unilaterally or bilaterally by injecting colchicines into the hippocampi of rats. Subsequently, we observed behavioural changes following the intraperitoneal injection of methamphetamine or saline. We also quantitatively assessed the expression of Fos protein in several brain regions, including the medial prefrontal cortex, cingulate cortex, piriform cortex, dorsal striatum, and nucleus accumbens, since these regions are innervated by dopaminergic terminals (Ungerstedt, 1971; Emson \& Koob, 1978; Lindvall et al., 1978; Loughlin \& Fallon, 1984; Datiche \& Cattarelli, 1996), and since methamphetamine administration has been seen to significantly induce Fos expression in all of these regions (Umino et al., 1995).

\section{Methods}

\section{Animals and surgery}

Male Sprague-Dawley rats weighting 220-240 g (Japan SLC, Japan) were used. The animals were housed 3-4 per cage in a temperature- and humidity-controlled colony room which was maintained on a 12-h light/dark cycle with lights on at $0600 \mathrm{~h}$. Food and water were freely available. The animals were divided into three groups: the bilaterally lesioned (BL) ( $n=16)$, unilaterally lesioned (UL) $(n=14)$, and control (C) $(n=14)$ groups. Colchicine was dissolved in saline at $10 \mu \mathrm{g} \mu \mathrm{l}^{-1}$. For bilateral lesions, the BL group animals were positioned in a stereotaxic apparatus under pentobarbitone anaesthesia ( $50 \mathrm{mg} \mathrm{kg}^{-1}$, i.p.), followed by bilateral injections of $0.5 \mu \mathrm{l}$ of $5 \mu \mathrm{g}$ colchicine into both the dorsal and ventral hippocampi over a period of 5 min using a microinjection pump (EP-60, EICOM, Japan). The coordinates were derived from the atlas of Paxinos and Watson (1986) $(3.3 \mathrm{~mm}$ posterior, $1.6 \mathrm{~mm}$ lateral, $3.7 \mathrm{~mm}$ deep for dorsal side; $5.3 \mathrm{~mm}$ posterior, $4.5 \mathrm{~mm}$ lateral, $5.6 \mathrm{~mm}$ deep for ventral side). The cannulae were left in place for an additional $2 \mathrm{~min}$ after the end of the infusion. The UL group was administered $0.5 \mu \mathrm{l}$ of colchicine $5 \mu \mathrm{g}$ solution into the right side of the dorsal and ventral hippocampi, and an equal volume of saline into the left side of the same regions, according to the same procedures described for the BL group. The $\mathrm{C}$ group received bilateral injections of $0.5 \mu \mathrm{l}$ of saline into the dorsal and ventral hippocampi.

\section{Behavioural observation}

Two weeks after injections of intrahippocampal colchicine or saline, behavioural changes in the $\mathrm{BL}$, UL, and $\mathrm{C}$ group animals were assessed after intraperitoneal injection of methamphetamine $(n=10$ for the BL group; $n=7$ for the UL group; $n=7$ for the $\mathrm{C}$ group) or saline ( $n=6$ for the $\mathrm{BL}$ group; $n=7$ for the UL group; $n=7$ for the $\mathrm{C}$ group). Methamphetamine was dissolved in saline at $2 \mathrm{mg} \mathrm{ml}^{-1}$.

For analysis of locomotor activity, an animal movement analysing system (SCANET SV-10, MATYS, Toyama, Japan) was used. The system included a rectangular enclosure $(480 \mathrm{~mm} \times 300 \mathrm{~mm})$ whose side walls $(60 \mathrm{~mm}$ high) were equipped with 144 pairs of photosensors located at $5 \mathrm{~mm}$ intervals. Each pair of photosensors was scanned every $0.1 \mathrm{~s}$ to detect animal movement. An intersection of two pairedphotosensors (10 $\mathrm{mm}$ interval) in the enclosure was counted as one unit of locomotor activity. Forty minutes before methamphetamine or saline injection, the animals were placed in a plastic cage $(260 \mathrm{~mm}$ wide, $440 \mathrm{~mm}$ long, and $400 \mathrm{~mm}$ high), which was positioned in the analysing system so that the enclosure's photosensors were set $30 \mathrm{~mm}$ above the cage floor. After collection of data for $40 \mathrm{~min}, 1 \mathrm{ml}$ (2 mg) $\mathrm{kg}^{-1}$ of methamphetamine or an equal volume of saline was administered intraperitoneally, followed by data collection for $90 \mathrm{~min}$. For assessment of rotational behaviour, animals were videotaped using a video camera positioned above the cage. The number of rotations in the direction of the lesioned (right) and non-lesioned (left) sides was counted. Subsequently, the net value expressed by the [(left rotations)-(right rotations)] was determined. Rotations were defined as complete $360^{\circ}$ turns.

\section{Immunohistochemistry for Fos protein}

Upon completion of the behavioural observations, i.e. $90 \mathrm{~min}$ after the methamphetamine or saline injection, all animals were deeply anaesthetized with pentobarbitone $\left(100 \mathrm{mg} \mathrm{kg}^{-1}\right.$, i.p.). They were then transcardially perfused with $100 \mathrm{ml}$ of $0.15 \mathrm{M} \mathrm{NaCl}$, followed by $500 \mathrm{ml}$ of ice-cold $4 \%$ paraformaldehyde in $0.1 \mathrm{M}$ phosphate buffer $(\mathrm{pH} 7.4)$. The brains were removed, post-fixed overnight at $4{ }^{\circ} \mathrm{C}$ in the same fixative for $24 \mathrm{~h}$, coronally sectioned at a thickness of $70 \mu \mathrm{m}$ using a vibratome (Leica VT1000S, Leica, Germany), and placed in ice-cold $0.01 \mathrm{M}$ phosphate-buffered saline ( $\mathrm{pH}$ 7.4). Free-floating sections were placed in $0.01 \mathrm{M}$ phosphatebuffered saline containing $2 \%$ normal goat serum, $0.2 \%$ Triton $\mathrm{X}-100$, and $0.1 \%$ bovine serum albumin for $1 \mathrm{~h}$ at room temperature. Sections were incubated for $36-48 \mathrm{~h}$ at $4{ }^{\circ} \mathrm{C}$ in a primary antibody (Fos $\mathrm{AB}-2$ rabbit polyclonal antibody, Oncogene Science, Cambridge, MA, U.S.A.) diluted $1: 1,000$. Sections were then washed twice in phosphate-buffered saline, incubated for $1 \mathrm{~h}$ in a second antibody (biotinylated goat anti-rabbit IgG adsorbed against rat serum), and incubated in an avidin-horseradish peroxidase solution prepared from the Vectastain ${ }^{\mathbb{R}}$ elite ABC kit (Vector Laboratories Inc., Burlingame, CA, U.S.A.) for $1 \mathrm{~h}$ at room temperature. Sections were washed twice in ice-cold phosphate-buffered saline $(\mathrm{pH}$ 7.4) and the antibody reaction 
was developed with 3,3'-diaminobenzidine $(0.015 \%)$ and $0.001 \%$ hydrogen peroxidase in $50 \mathrm{~mm}$ Tris $\mathrm{HCl}(\mathrm{pH} \mathrm{7.4})$. After several rinses in phosphate-buffered saline ( $\mathrm{pH} 7.4)$, the stained sections were mounted on gelatinized slides, dehydrated, and coverslipped with Permount ${ }^{\mathbb{R}}$ (Fisher Scientific Co., Fair Lawn, NJ, U.S.A.).

For quantitative analysis, the number of Fos immunoreactive neurons within a $0.35 \mathrm{~mm}^{2}$ area was counted, blind to the animal's status, using an Apple Macintosh with image analysis software (NIH Image). The anatomical identifications of sections were made according to the atlas of Paxinos and Watson (1986). The regions (AP coordinates) analysed were the medial prefrontal cortex (3.2 $\mathrm{mm}$ anterior), cingulate cortex (1.7 $\mathrm{mm}$ anterior), piriform cortex (1.7 $\mathrm{mm}$ anterior), dorsal striatum $(1.7 \mathrm{~mm}$ anterior), and nucleus accumbens (1.7 $\mathrm{mm}$ anterior)

For examination of granule cells, sections prepared for Fos immunohistochemistry were stained with cresyl violet.

\section{Drugs}

Colchicine was purchased from Sigma Chemical Co. (St. Louis, MO, U.S.A.). Methamphetamine was obtained from Dai-nippon Pharmaceutical Co., Ltd. (Osaka, Japan).

\section{Statistical analysis}

The main dependent variables were the number of locomotor activities, net rotations, and Fos immunoreactive cells. Twoway analysis of variance (ANOVA) was conducted to test the effects of 'Lesion' (C, UL, and BL) and 'Drug' (saline and methamphetamine) on these dependent variables. When significant interaction of Lesion and Drug were revealed by ANOVA, we subsequently repeated one-way ANOVA for Drug group separately (i.e., saline $v s$ methamphetamine) to see whether any distinct patterns of the dependent variables across three levels of Lesion would emerge between the Drug groups. According to the results of one-way ANOVA, we further carried out post hoc pair comparisons using the Fisher's Least Significant Difference (LSD) test. In addition, we examined, using paired $t$-test, any within-animal differences in the number of Fos immunoreactive cells between left and right sides of five brain regions studied in each of the three Lesion groups (i.e., laterality). All the values are shown as mean \pm standard error of the mean (s.e.mean) in the text. The statistically significant level was set at $P<0.05$. Analyses were carried out with the SPSS package for Windows, version 7.5 (SPSS Inc., Chicago, Illinois, U.S.A.).

\section{Results}

\section{Histological examination for granule cell destruction}

The histological examination indicated that intrahippocampal colchicine caused almost complete destruction of granule cells (Figure 1A). In addition, the pyramidal cells in the CA fields were stained much more lightly after colchicine treatment compared with those after saline injection (Figure 1A,B). The light staining of the pyramidal cells were comparable with the finding of a previous study (Goldschmidt \& Steward, 1982). In that study, however, most lightly stained cells returned to
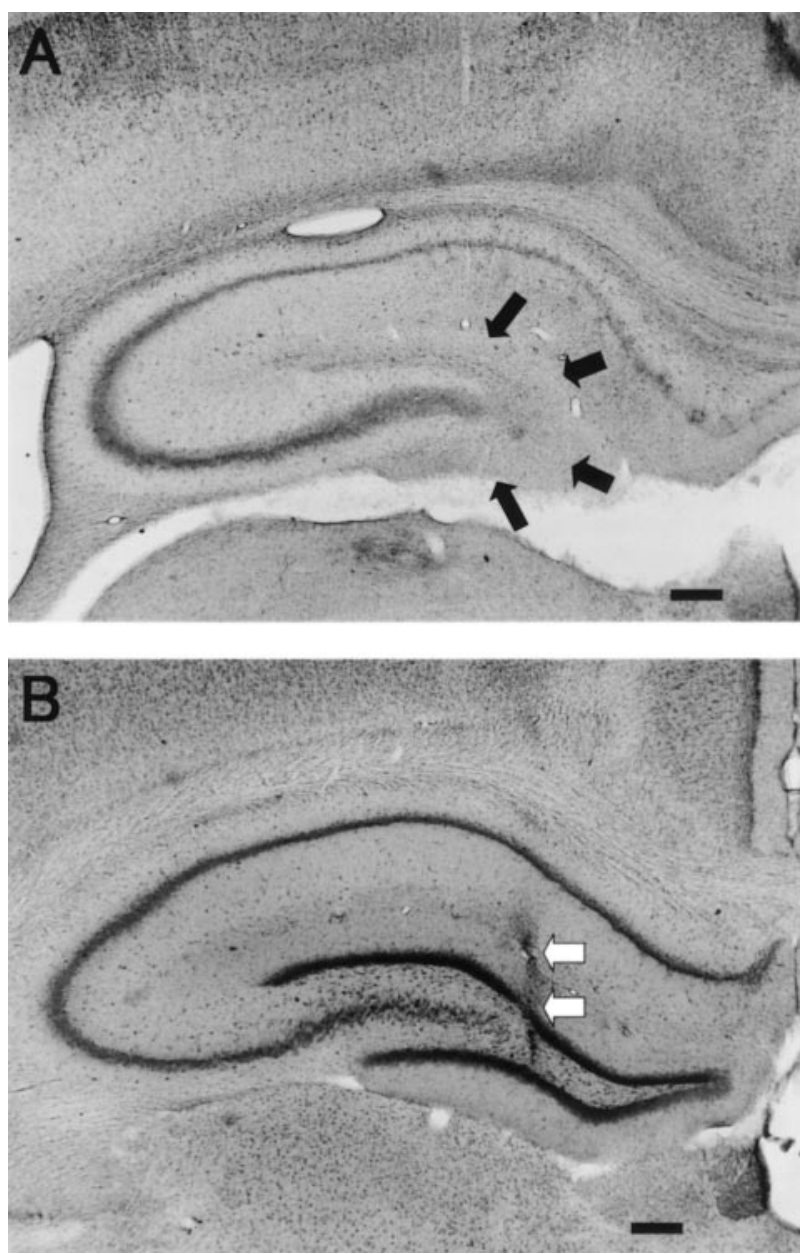

Figure 1 Morphological effects of intrahippocampal colchicine (A) or saline (B). Coronal sections of the dorsal hippocampus stained with cresyl violet are shown. The granule cells are almost completely destroyed by colchicine (black arrowheads) (A). The white arrowheads show the insertion track of the cannulae used for injecting saline (B). The calibration bar is $500 \mu \mathrm{m}$.

normal staining intensity 60 days after intrahippocampal colchicine even at the $25 \mu \mathrm{g}$ dose. Therefore, the pale-stained neurons in the CA fields apparently survived (Goldschmidt \& Steward, 1982).

\section{Behavioural observation}

During the 40-min period before treatment with saline or methamphetamine, there were no behavioural differences among the C, UL, and BL groups. The number of locomotor activities for $90 \mathrm{~min}$ after saline injection was $3,125.3 \pm 910.8$ in the $\mathrm{C}$ group, $2,749.8 \pm 828.2$ in the UL group, and $15,979.2 \pm 2,974.2$ in the BL group animals (Figure 2). The methamphetamine-induced locomotor activity was 49,041.6 \pm $2,245.8$ in the $\mathrm{C}$ group, $49,166.3 \pm 8,465.5$ in the UL group, and $103,382.3 \pm 3,340.1$ in the BL group animals (Figure 2). There was a significant interaction of Lesion and Drug in the number of locomotor activity $(\mathrm{F}=14.41, \quad$ d.f. $=2, \quad 38$, $P<0.001)$. One-way ANOVA showed the significant difference among three Lesion groups after both saline $(F=18.47$, d.f. $=2,17, P<0.001)$ and methamphetamine administration $(\mathrm{F}=34.36$, d.f. $=2,21, P<0.001)$. The $\mathrm{BL}$ group showed a 
significantly larger number of locomotions after saline injection than did the $\mathrm{C}(P<0.001)$ and $\mathrm{UL}(P<0.001)$ group animals, although the latter two groups showed no significant differences $(P=0.88)$. With methamphetamine treatment, the $\mathrm{BL}$ group animals showed a significantly larger number of locomotions than did the $\mathrm{C}(P<0.001)$ and UL $(P<0.001)$ group animals, while the latter two groups showed a similar amount of locomotions $(P=0.23)$.

Rotational responses to saline or methamphetamine are summarized in Table 1, where there was a strong Lesion $\mathrm{X}$ Drug interaction in the number of net rotations $(\mathrm{F}=12.1$, d.f. $=2, \quad 38, \quad P<0.001)$. One-way ANOVA showed the significant difference among three Lesion groups after methamphetamine administration $(\mathrm{F}=13.83$, d.f. $=2,21$, $P<0.001)$, whereas there was no significant difference among the saline treatment groups $(\mathrm{F}=0.33$, d.f. $=2,17, P=0.72)$. The number of net rotations for the UL group animals after methamphetamine injection was significantly larger than that for the $\mathrm{C}(P<0.001)$ and $\mathrm{BL}(P<0.001)$ group animals.

\section{Immunohistochemistry for Fos protein}

Induction of Fos protein was found in all regions tested after saline or methamphetamine injection (Figure 3A,B). Twoway ANOVA revealed a significant Lesion $\mathrm{X}$ Drug interaction in the number of Fos-positive cells on both sides of all regions except the right piriform cortex: $F=4.74$,

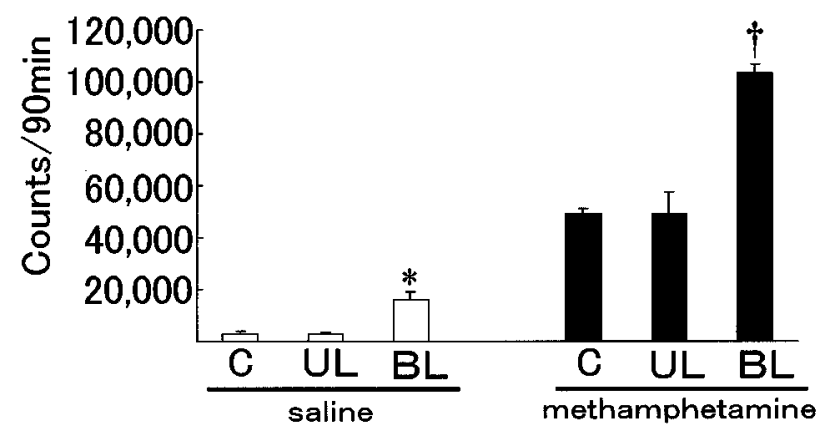

Figure 2 Amount of locomotor activity after saline or methamphetamine administration in the $\mathrm{C}, \mathrm{BL}$, and UL group animals. The amount of locomotion in the BL group was significantly larger than that for the $\mathrm{C}\left({ }^{*} P<0.001\right)$ and UL group $(* P<0.001)$ after saline administration, while the latter two groups showed no significant difference $(P=0.88)$. After methamphetamine administration, the value for the $\mathrm{BL}$ group was markedly larger than that for the $\mathrm{C}$ $(\dagger P<0.001)$ and UL group $(\dagger P<0.001)$, while there was no significant difference in locomotion between the latter two groups $(P=0.23)$.

Table 1 Net values expressed by the [(left rotations) - (right rotations)] in the $\mathrm{C}$, UL and $\mathrm{BL}$ group animal following saline or methamphetamine injection

$\begin{array}{lrc} & \text { Saline } & \text { Methamphetamine } \\ \mathrm{C} & -0.4 \pm 0.4(n=7) & -0.7 \pm 28.8(n=7) \\ \mathrm{UL} & 0 \pm 0.4(n=7) & 321.7 \pm 59.8^{*}(n=7) \\ \mathrm{BL} & 0.3 \pm 1.1(n=6) & 30.2 \pm 43.0(n=10)\end{array}$

Values are means \pm s.e.mean. ${ }^{*} P<0.001$, compared with the corresponding value for the $\mathrm{C}$ and $\mathrm{BL}$ groups after methamphetamine administration.
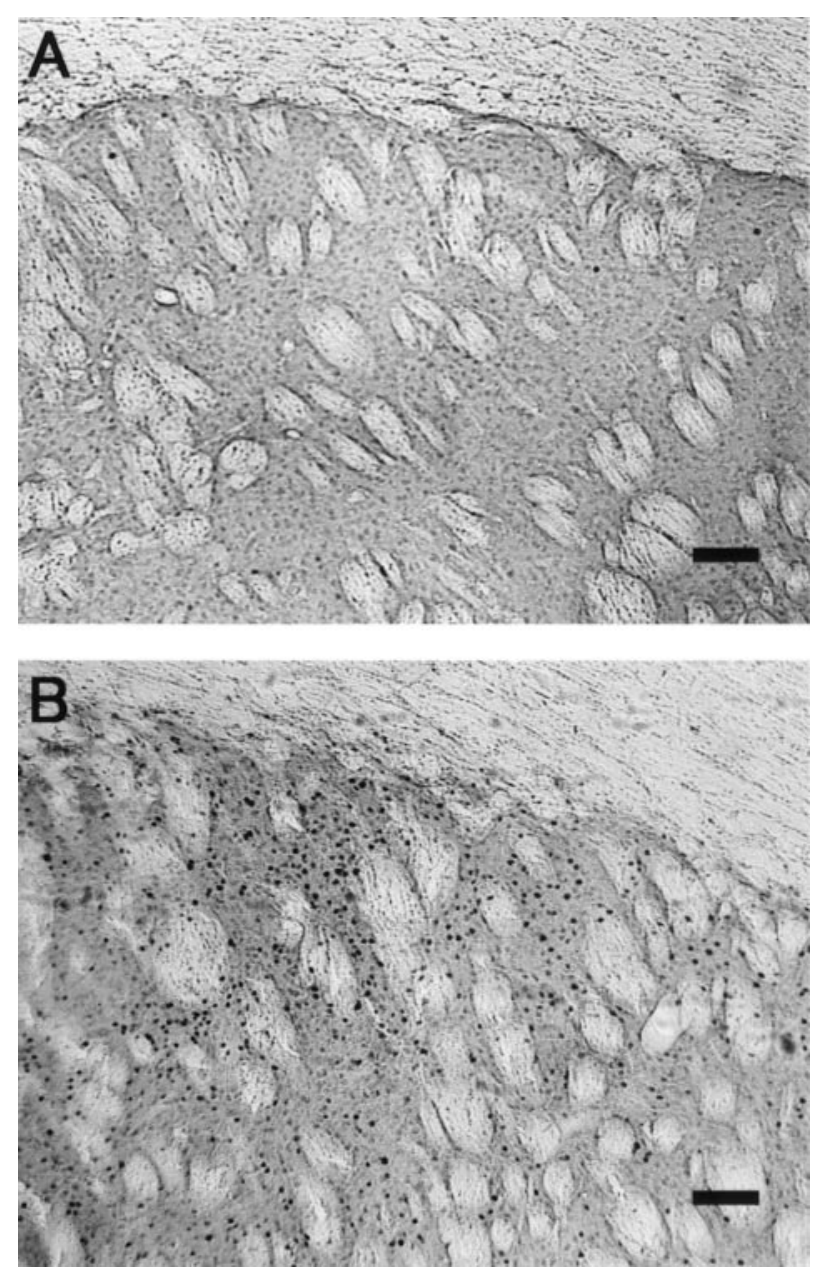

Figure 3 The induction of Fos protein in the dorsal striatum after saline (A) or methamphetamine administration (B), each from the BL group. The calibration bar is $100 \mu \mathrm{m}$.

d.f. $=2,38, \quad P=0.015$ for the right side and $\mathrm{F}=9.91$, d.f. $=2,38, P<0.001$ for the left side in the medial prefrontal cortex; $\mathrm{F}=6.51$, d.f. $=2,38, P=0.004$ for the right side and $\mathrm{F}=5.64, \quad d . f .=2,38, \quad P=0.007$ for the left side in the cingulate cortex; $\mathrm{F}=9.02$, d.f. $=2,38, P=0.001$ for the right side and $\mathrm{F}=19.99, d_{.} f=2,38, P<0.001$ for the left side in the dorsal striatum; $\mathrm{F}=7.32$, d.f. $=2,38, P=0.002$ for the right side and $\mathrm{F}=5.48$, d.f. $=2,38, P=0.008$ for the left side in the nucleus accumbens; $\mathrm{F}=4.18, d . f$. $=2,38, P=0.023$ for the left side and $\mathrm{F}=2.13$, d.f. $=2,38, P=0.13$ for the right side in the piriform cortex (Figure 4). For the right side of the piriform cortex, there were significant main effects of Lesion $(\mathrm{F}=5.95$, d.f. $=2,40, \quad P=0.005)$ and Drug $(\mathrm{F}=64.12, \quad$ d.f. $=1,40$, $P<0.001)$. In both sides of all regions except the nucleus accumbens, subsequent one-way ANOVA revealed that these significant interactions were attributable to the fact that there were no overall significant Lesion differences in the number of Fos immunoreactive cells for the saline treatment group, while significant differences were evident across the three Lesion groups for methamphetamine treatment animals: $\mathrm{F}=5.86, \quad d . f .=2,21, \quad P=0.010$ for the right side and $\mathrm{F}=13.07$, d.f. $=2,21, P<0.001$ for the left side in the medial prefrontal cortex; $\mathrm{F}=9.63$, d.f. $=2,21, P=0.001$ for the right side and $\mathrm{F}=7.72$, d.f. $=2,21, P=0.003$ for the left side in the 
MEDIAL PREFRONTAL CORTEX
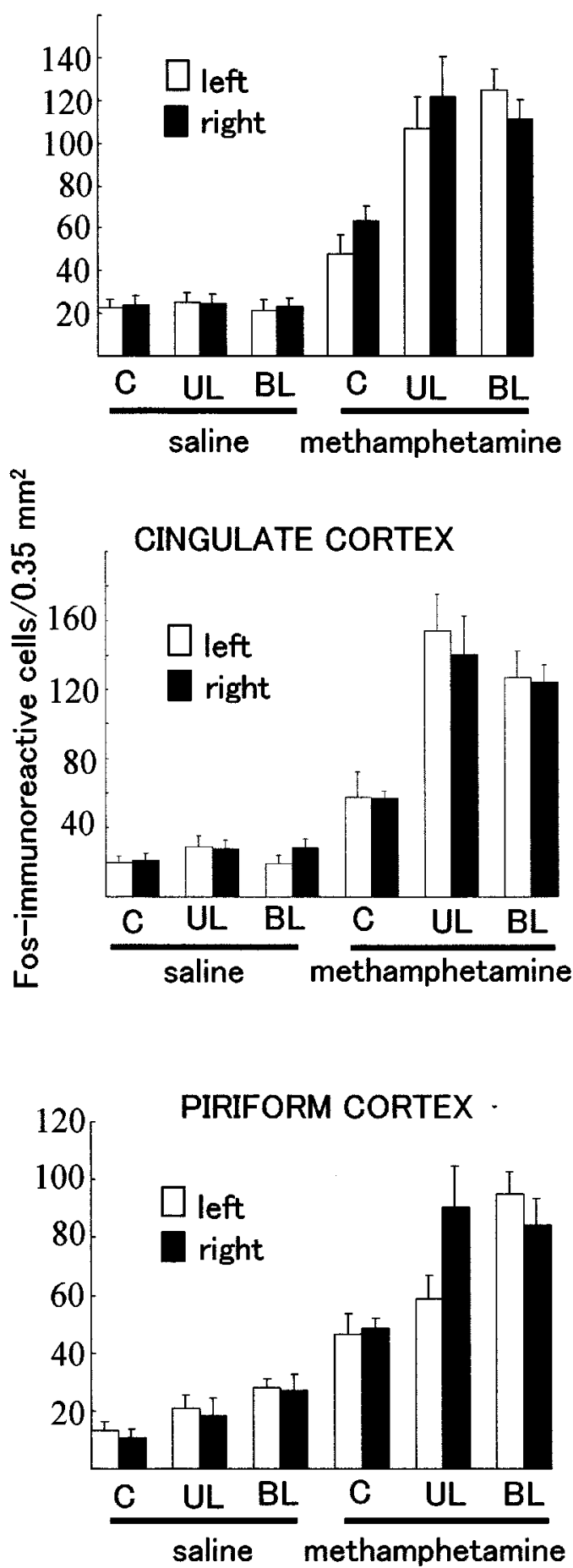

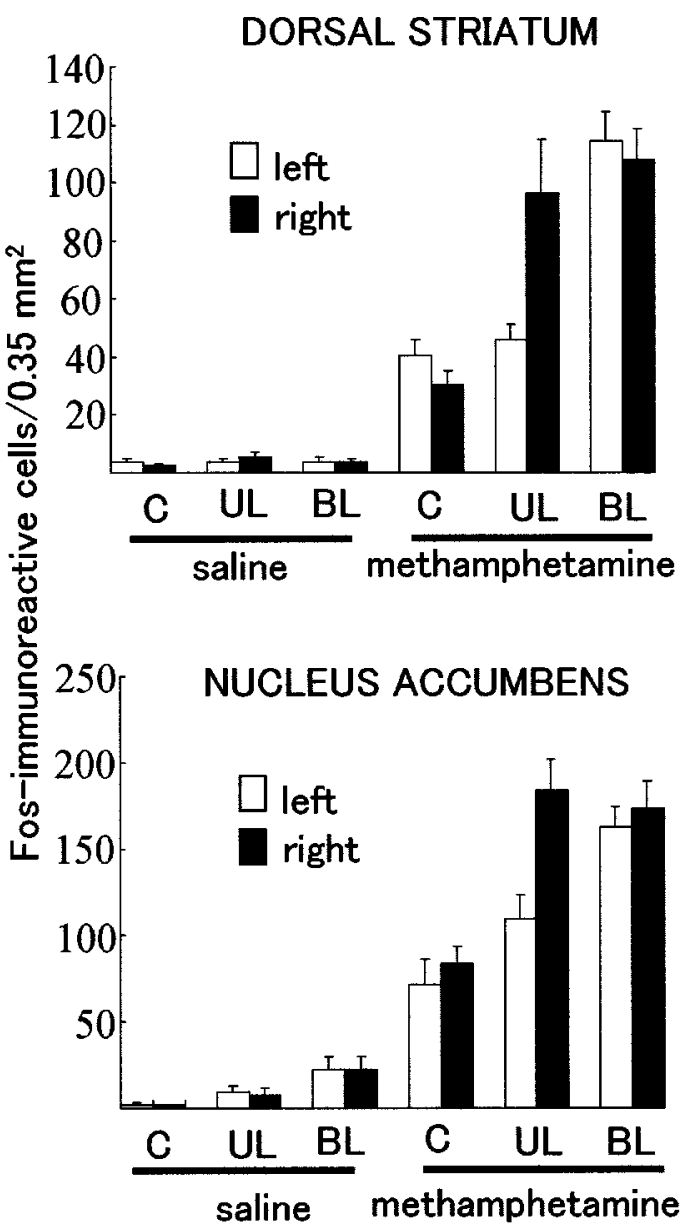

Figure 4 The number of Fos-positive cells in the medial prefrontal cortex, cingulate cortex, piriform cortex, dorsal striatum, and nucleus accumbens following saline or methamphetamine administration. The white bars are for the left sides in the regions and the black bars are for the right sides. Error bars indicate s.e.mean. See also Tables 2A and B for post hoc pair comparisons.

cingulate cortex; $\mathrm{F}=13.10$, d.f. $=2,21, P<0.001$ for the right side and $\mathrm{F}=26.83$, d.f. $=2,21, P<0.001$ for the left side in the dorsal striatum; $\mathrm{F}=4.97$, d.f. $=2,21, P=0.017$ for the right side and $\mathrm{F}=12.19$, d.f. $=2,21, P<0.001$ for the left side in the piriform cortex. In contrast, in both sides of the nucleus accumbens, there were the significant differences across three Lesion groups for both the saline $(\mathrm{F}=6.47$, d.f. $=2,17$,
$P=0.008$ for the right side and $\mathrm{F}=5.28$, d.f. $=2,17$, $P=0.016$ for the left side) and methamphetamine $(\mathrm{F}=11.27$, d.f. $=2,21, \quad P<0.001$ for the right side and $\mathrm{F}=12.48$, d.f. $=2,21, P<0.001$ for the left side) treatment animals.

Based on the significant one-way ANOVA results, we proceeded to carry out post hoc pair comparisons. In the 
Table 2A Post hoc analysis of the number of Fos immunoreactive cells among the three Lesion groups after methamphetamine administration

\begin{tabular}{|c|c|c|c|c|c|c|c|c|c|c|}
\hline & \multicolumn{2}{|c|}{ Medial prefrontal cortex } & \multicolumn{2}{|c|}{ Cingulate cortex } & \multicolumn{2}{|c|}{ Piriform cortex } & \multicolumn{2}{|c|}{ Dorsal striatum } & \multicolumn{2}{|c|}{ Nucleus accumbens } \\
\hline & Right & Left & Right & Left & Right & Left & Right & Left & Right & Left \\
\hline $\mathrm{C}<\mathrm{UL}$ & $* *$ & $* *$ & $* *$ & $* *$ & $* *$ & ns & $* *$ & ns & $* * *$ & ns \\
\hline $\mathrm{C}<\mathrm{BL}$ & $*$ & $* * *$ & $* *$ & $* *$ & $*$ & $* * *$ & $* * *$ & $* * *$ & $* * *$ & $* * *$ \\
\hline $\mathrm{UL}<\mathrm{BL}$ & ns & $\mathrm{ns}$ & ns & ns & ns & $* *$ & ns & $* * *$ & ns & $*$ \\
\hline
\end{tabular}

methamphetamine treatment animals, the $\mathrm{BL}$ and $\mathrm{UL}$ groups, when compared to $\mathrm{C}$ group, showed a significantly greater increase in the number of immunoreactive cells in both sides of the medial prefrontal cortex and cingulate cortex (see Table 2A for post hoc pair comparisons). There was no significant difference between the BL and UL groups in these regions. Similarly, in the right side of the piriform cortex, dorsal striatum, and nucleus accumbens, the BL and UL groups showed a significant difference compared to $\mathrm{C}$ group, whereas there was no significant difference between the BL and UL groups in these regions. In the left side of the piriform cortex, dorsal striatum, and nucleus accumbens, the number of Fos-positive cells for the BL group was significantly elevated compared to that of the $\mathrm{C}$ and $\mathrm{UL}$ groups. The UL group did not show a significantly greater increase in the number of immunoreactive cells compared to $\mathrm{C}$ group in these regions.

In both sides of the nucleus accumbens, in the saline administration animals, the number of Fos-positive cells significantly increased in the BL group compared to in the $\mathrm{C}$ and UL groups (see Table 2B for post hoc pair comparisons).

The C, UL, and BL groups, in the saline treatment animals, showed no significant laterality in the number of Fos-positive cells in any regions tested (Figure 4). For the methamphetamine treatment animals, no marked or significant laterality in Fos expression was noted in either of the three Lesion groups in the medial prefrontal cortex and cingulate cortex. In the piriform cortex, dorsal striatum, and nucleus accumbens, the $\mathrm{BL}$ and $\mathrm{C}$ group showed no significant laterality. For the UL group, however, the number of Fos-immunoreactive cells on the right side was significantly larger than that for the left side $(P=0.032$ for the piriform cortex, $P=0.025$ for the dorsal striatum, and $P=0.014$ for the nucleus accumbens).

\section{Discussion}

The findings of present study confirm those of previous studies demonstrating an increase in locomotor activity and rotation after systemic injection of methamphetamine (Jerussi \& Glick, 1974; Hirabayashi \& Alam, 1981; Sato et al., 1992; Iyo et al., 1995). The present findings also show that the methamphetamine-induced locomotor is greatly enhanced by the bilateral destruction of hippocampal granule cells, while their unilateral destruction resulted in a marked increase in the rotation contralateral to the lesioned side without a marked change in locomotor activity. These observations suggest that bilateral granule cell destruction increases locomotor activity, while unilateral granule cell destruction induces contralateral rotation. Previously, it has been
Table 2B Post hoc analysis of the number of Fos immunoreactive cells among the three Lesion groups after saline administration

\begin{tabular}{lcc} 
& \multicolumn{2}{c}{ Nucleus accumbens } \\
& Right & Left \\
$\mathrm{C}<\mathrm{UL}$ & $\mathrm{ns}$ & $\mathrm{ns}$ \\
$\mathrm{C}<\mathrm{BL}$ & $* *$ & $* *$ \\
$\mathrm{UL}<\mathrm{BL}$ & $*$ & $*$
\end{tabular}

ns: non-significant difference; ${ }^{*} P<0.05 ; * * P<0.01$.

reported that hippocampal lesions enhanced amphetamineinduced locomotor activity and rotational activity (Glick et al., 1980; Whishaw \& Mittleman, 1991; Lipska et al., 1992; Mittleman et al., 1993; Wilkinson et al., 1993; Schaub et al., 1997). However, this is the first report demonstrating that destruction of the dentate gyrus enhances systemic methampetamine-induced locomotor activity and rotations.

Methamphetamine administration significantly increased the number of Fos-positive cells in the medial prefrontal cortex, cingulate cortex, piriform cortex, dorsal striatum, and nucleus accumbens compared to vehicle-treated animals. This finding is consistent with previous studies showing that systemic methamphetamine elicits a robust emergence of Fospositive cells in several brain areas of the rat (Umino et al., 1995). This is the first study to report that the destruction of dentate granule cells enhanced methamphetamine-induced Fos protein expression in the medial prefrontal cortex, cingulate cortex, piriform cortex, dorsal striatum, and nucleus accumbens.

Although destruction of the hippocampal granule cells influenced methamphetamine-induced behavioural changes and Fos expression, the relationship between the behavioural changes and Fos expression remains unclear based on the findings of the present study alone. The possibility cannot be excluded that the enhanced expression of Fos protein is due merely to the pharmacological effects of methamphetamine, which are independent of behavioural changes. However, with respect to the nucleus accumbens, dorsal striatum, and piriform cortex in which unilateral lesioning induced ipsilateral enhancement of Fos expression, previous findings may shed light on this issue. The nucleus accumbens is known to actively participate in both locomotor and rotational activities induced by amphetamine or dopamine (Pijnenburg \& Van Rossum, 1973; Kelly et al., 1975; Staton \& Solomon, 1984; Colle \& Wise, 1991). The striatum may be involved in rotational behaviour (Ungerstedt \& Arbuthnott, 1970; Joyce et al., 1981), while its role in locomotor activity is believed to be minimal (Kelly et al., 1975; Staton \& Solomon, 1984). Although there is no available information regarding 
the locomotion associated with the dopaminergic function in the piriform cortex, there is evidence suggesting that this structure may participate in rotational behaviour (Ormond \& Hartesveldt, 1979). Taken together, the unilateral destruction of dentate granule cells may induce ipsilateral hyperactivity in the nucleus accumbens, dorsal striatum, and piriform cortex following methamphetamine administration, characterized by contralateral rotations associated with the ipsilateral enhancement of Fos expression. Following the bilateral destruction of granule cells, the nucleus accumbens appears to be in a hyperactive state as both locomotor and Fos expression were enhanced. However, the bilateral activation of the dorsal striatum and piriform cortex after bilateral destruction of the granule cells may not play a critical role in locomotor activity. However, the above assumptions remain to be definitively proven.

Due to the sequential nature of the hippocampus, in which information travels from the dentate gyrus to CA3 to CA1 to the subiculum, granule cell destruction may disrupt or modify the function of the efferent system from the hippocampus, which is mediated by the subiculum. The subiculum sends a large glutamergic output to the nucleus accumbens (DeFrance et al., 1980; Christie et al., 1987), and there is evidence that glutamate can modulate dopamine release presynaptically (Imperato et al., 1990; Shimizu et al., 1990). The subiculum also sends efferents to the dorsal striatum (Groenewegen et al., 1987), and there appears to be a marked overlap between regions innervated by the subiculum and areas showing high immunoreactivity for cholecystokinin (Zaborszky et al., 1985), which may regulate the release of dopamine from presynaptic sides (Rehfeld, 1985). Although there is no available information regarding the fibre

\section{References}

ANTONIOU, K. \& KAFETZOPOULOS, E. (1992). Behavioural effects of amphetamine and apomorphine after striatal lesions in the rat. Phamacol. Biochem. Behav., 43, 705-722.

BERTRAM, E.H., ZHANG, D.X., MANGAN, P., FOUNTAIN, N. \& REMPE, D. (1998). Functional anatomy of limbic epilepsy: a proposal for central synchronization of a diffusely hyperexcitable network. Epilepsy Res., 32, 194-205.

CARBONI, E., IMPERATO, A., PEREZZANI, L. \& DI CHIARA, G (1989). Amphetamine, cocaine phencyclidine and nomifensine increase extracellular dopamine concentrations preferentially in the nucleus accumbens of freely moving rats. Neuroscience, $\mathbf{2 8}$ $653-661$.

CHRISTIE, M.J., SUMMERS, R.J., STEPHENSON, J.A., COOK, C.J. \& BEART, P.M. (1987). Excitatory amino acid projections to the nucleus accumbens septi in the rat: a retrograde transport study utilizing $\mathrm{D}\left[{ }^{3} \mathrm{H}\right]$ aspartate and $\left[{ }^{3} \mathrm{H}\right] \mathrm{GABA}$. Neuroscience, 22, $425-$ 439.

COLlE, L.M. \& WISE, R.A. (1991). Circling induced by intraaccumbens amphetamine injections. Psychopharmacol., 105, $157-161$.

DATICHE, F. \& CATTARELLI, M. (1996). Catecholamine innervation of the piriform cortex: a tracing and immunohistochemical study in the rat. Brain Res., 710, 69-78.

DEFRANCE, J.F., MARCHAND, J.E., STANLEY, J.C., SIKES, R.W. \& CHRONISTER, R.B. (1980). Convergence of excitatory amygdaloid and hippocampal input in the nucleus accumbens septi. Brain Res., 185, $183-186$

EMERICH, D.F. \& WALSH, T.J. (1990). Hyperactivity following intradentate injection of colchicine: a role for dopamine systems in the nucleus accumbens. Phamacol. Biochem. Behav., 37, 149 154. connections between the hippocampus and piriform cortex, it is well-known that electrical stimulation of the former structure readily causes neuronal firing of the ipsilateral latter region (Bertram et al., 1998). These subicular projections to the nucleus accumbens, dorsal striatum, and piriform cortex are mainly ipsilateral. Therefore, ipsilateral activation of Fos expression in these three regions after unilateral lesioning may be mediated by the interception of these projections. Anatomical and physiological studies have shown bidirectional and reciprocal connections between the hippocampus and medial prefrontal cortex (Jay et al., 1989; White et al., 1990; Jay \& Witter, 1991). Similar connections between the hippocampus and cingulate cortex have also been documented (White et al., 1990; Jay \& Witter, 1991). These connections are mainly ipsilateral. Nevertheless, the unilateral lesioning resulted in a bilateral increase in Fos expression in both the prefrontal cortex and cingulate cortex. Therefore, the increased density of Fos expression in both of these structures may be mediated by the polysynaptic pathways.

In conclusion, the present findings suggest that dentate granule cells regulate methamphetamine-associated behavioural changes through altering the function of a number of brain areas, particularly the nucleus accumbens. Additional studies must be conducted to further delineate the roles of the various brain areas in mediating the response to methamphetamine following the destruction of granule cells in the hippocampus.

The authors are most grateful to acknowledge valuable discussions with Dr Yoshio Minabe (Hamamatsu University School of Medicine).

EMSON, P.C. \& KOOB, G.F. (1978). The origin and distribution of dopamine-containing afferents to the rat frontal cortex. Brain Res., 142, $249-267$.

GLICK, S.D., MEIBACH, R.C., COX, R.D. \& MAAYANI, S. (1980). Phencyclidine-induced rotational and hippocampal modulation of nigrostriatal asymmetry. Brain Res., 196, 99-107.

GOLDSCHMIDT, R.B. \& STEWARD, O. (1982). Neurotoxic effects of colchicines: Differential susceptibility of CNS neuronal populations. Neuroscience, 7, 695-714.

GROENEWEGEN, H.J., VERMEULEN-VAN DER ZEE, E., TE KORTSCHOT, A. \& WITTER, M.P. (1987). Organization of the projections from the subiculum to the ventral striatum in the rat. A study using anterograde transport of Phaseolus vulgaris leucoagglutinin. Neuroscience, 23, 103-120.

HIRABAYASHI, M. \& ALAM, M.R. (1981). Enhancing effect of methamphetamine on ambulatory activity produced by repeated administration in mice. Pharmacol. Biochem. Behav., 15, $925-$ 932.

IMPERATO, A., HONORE, T. \& JENSEN, L.H. (1990). Dopamine release in the nucleus caudatus and in the nucleus accumbens is under glutamatergic control through non-NMDA receptors: a study in freely moving rats. Brain Res., 530, 223-228.

IYO, M., MAEDA, Y., INADA, T., KITAO, Y., SASAKI, H. \& FUKUI, S. (1995). The effect of a selective camp phosphodiesterase Inhibitor, Rolipram, on Methamphetamine-induced behavior. Neuropsychopharmacology, 13, 33-39.

JAY, T.A., GLOWINSKI, J. \& THIERRY, A.M. (1989). Selectivity of the hippocampal projection to the prelimbic area of the prefrontal cortex in the rat. Brain Res., 505, 337-340. 
JAY, T.A. \& WITTER, M.P. (1991). Distribution of hippocampal CA1 and subicular efferents in the prefrontal cortex of the rat studied by means of anterograde transport of Phaseolus vulgarisleucoagglutinin. J. Comp. Neurol., 313, 574-586.

JERUSSI, T.P. \& GLICK, S.D. (1974). Amphetamine-induced rotation in rats without lesions. Neuropharmacology, 13, 283-286.

JOYCE, J.N., DAVIS, R.E. \& HARTESVELDT, C.V. (1981). Behavioural effects of unilateral dopamine injection into dorsal or ventral striatum. Eur. J. Pharmacol., 72, $1-10$.

KELLY, P.H., SEVIOUR, P.W. \& IVERSEN, S.D. (1975). Amphetamine and apomorphine responses in the rat following 6-OHDA lesions of the nucleus accumbens septi and corpus striatum. Brain Res., 94, $507-522$.

LINDVALL, O., BJÖRKLUND, A. \& DIVAC, I. (1978). Organization of catecholamine neurons projecting to the frontal cortex in the rat. Brain Res., 142, 1 - 24.

LIPSKA, B.K., JASKIW, G.E., CHRAPUSTA, S., KAROUM, F. \& WEINBERGER, D.R. (1992). Ibotenic acid lesion of the ventral hippocampus differentially affects dopamine and its metabolites in the nucleus accumbens and prefrontal cortex in the rat. Brain Res., 585, $1-6$.

LOUGHLIN, S.E. \& FALLON, J.H. (1984). Substantia nigra and ventral tegmental area projections to cortex: topography and collateralization. Neuroscience, 11, 425-435.

MITTLEMAN, G., LEDUC, P.A. \& WHISHAW, I.Q. (1993). The role of D1 and D2 receptors in the heightened locomotion induced by direct and indirect dopamine agonists in rats with hippocampal damage: an animal analogue of schizophrenia. Behav. Brain Res., $\mathbf{5 5}, 253-267$.

MORGAN, J.I. \& CURREN, T. (1991). Stimulus-transcription coupling in the nervous system: involvement of inducible proto-oncogenes fos and jun. Ann. Rev. Neurosci., 14, 421-451.

ORMOND, D.L. \& HARTESVELDT, C.V. (1979). Functional development of dopamine receptors in the rat forebrain. Phamacol. Biochem. Behav., 10, 855-860.

PAXINOS, G. \& WATSON, C. (1986). The Rat Brain in Stereotaxic Coordinates. San Diego, CA.: Academic Press.

PIJNENBURG, A.J. \& VAN ROSSUM, J.M. (1973). Stimulation of locomotor activity following injection of dopamine into the nucleus accumbens. J. Pharm. Pharmacol., 25, $1003-1005$.

REHFELD, J.F. (1985). Neuronal cholecystokinin: one or multiple transmitters? J. Neurochem., 44, 1-10.
SATO, M., NUMACHI, Y. \& HAMAMURA, T. (1992). Relapse of paranoid psychotic state in methamphetamine model of schizophrenia. Schizophrenia Bull., 18, 115-122.

SCHAUB, C.L., SCHMELZEIS, M.C. \& MITTLEMAN, G. (1997). The effects of limbic lesions on locomotion and stereotypy elicited by dopamine agonists in the rat. Behav. Brain Res., 84, 129-143.

SHIMIZU, N., DUAN, S., HORI, T. \& OOMURA, Y. (1990). Glutamate modulates dopamine release in the striatum as measured by brain microdialysis. Brain Res. Bull., 25, 99-102.

STATON, D.M. \& SOLOMON P.R. (1984). Microinjections of damphetamine into the nucleus accumbens and caudate-putamen differentially affect stereotypy and locomotion in the rat. Physiological Psychology, 12, 159-162.

UMINO, A., NISHIKAWA, T. \& TAKAHASHI, K. (1995). Methamphetamine-induced nuclear c-Fos in rat brain regions. Neurochem. Int., 26, $85-90$.

UNGERSTEDT, U. (1971). Stereotaxic mapping of the monoamine pathway in the rat brain. Acta Physiol. Scand., 83, suppl. 367, 1 48.

UNGERSTEDT, U. \& ARBUTHNOTT, G.W. (1970). Quantitative recording of rotational behaviour in rats after 6-hydroxydopamine lesions of the nigrostriatal dopamine system. Brain Res., 24, $485-493$.

WHISHAW, I.Q. \& MITTLEMAN, G. (1991). Hippocampal modulation of nucleus accumbens: behavioural evidence from amphetamineinduced activity profiles. Behav. Neural Biol., 55, 289-306.

WHITE, T.D., TAN, A.M. \& FINCH, M. (1990). Functional reciprocal connections of the rat entorhinal cortex and subicular complex with the medial frontal cortex: an in vivo intracellular study. Brain Res., 533, $95-106$.

WILKINSON, L.S., MITTLEMAN, G., TORRES, E., HUMBY, T., HALL, F.S. \& ROBBINS, T.W. (1993). Enhancement of amphetamineinduced locomotor activity and dopamine release in nucleus accumbens following excitotoxic lesions of the hippocampus. Behav. Brain Res., 55, 143-150.

ZABORSZKY, L., ALHEID, G.F., BEINFELD, M.C., EIDEN, L.E., HEIMER, L. \& PALKOVITS, M. (1985). Cholecystokinin innervation of the ventral striatum: a morphological and radioimmunological study. Neuroscience, 14, 427-453.

(Received January 5, 2001 Revised August 8, 2001 Accepted September 6, 2001) 